\title{
Taking airflow technology to the max
}

With the launch of the brand-new AirFlow Max from EMS, clinicians are able to offer their patients maximum efficiency, comfort and safety when performing guided biofilm therapy (GBT).

Guided biofilm therapy (GBT) is a systematic, predictable solution for dental biofilm management in professional prophylaxis using state-of-the-art airflow technologies.

AirFlow Max's revolutionary design incorporates Guided Laminar AirFlow Technology, a precise synergy between air, powder and water that achieves this new level of safety, efficiency and comfort for patients and clinicians.

The laminar flow reaches the treatment surface in a smooth, accurate and focused linear pattern to maximise powder use and visibility.

In addition, the ergonomic design with slimmer grip and reduced weight enhances ease of use and clinician comfort.

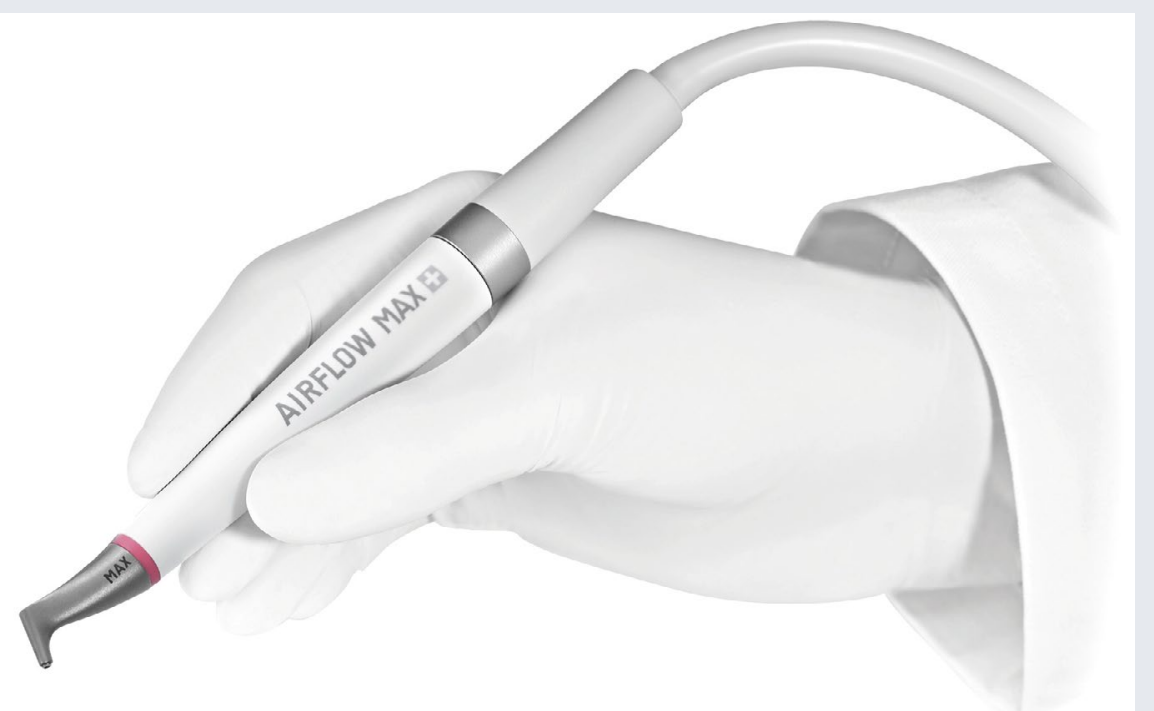

If you would like further details about what EMS Dental has to offer dental professionals in the UK, visit www.ems-dental.com.

\section{Consult with your patients interactively}

Dental Protection has announced a new partnership with Chairsyde, a system which helps dental professionals consult with patients interactively.

Developed by dentists, for dentists, it is designed to educate patients about their oral health both virtually through teledentistry and alongside supporting face-to-face discussions in practice. It offers visual aids that can be annotated to explain diagnosis and treatment plans, and enables patients to log in and view their treatment plan, replay the animations linked to their consultation, and contact their dentist directly to ask questions.

Chairsyde records the patient journey right from their first consultation and includes date stamped evidence of visuals shown and information communicated to patients as part of the consent process.

The partnership comes as a Dental Protection survey of nearly 200 UK dental professionals found that the majority of dentists have been using teledentistry, with $88 \%$ believing the changes would continue beyond COVID-19. However, technology was a barrier for many, with $62 \%$ finding that their patients do not have access to the technology. Forty-eight percent of the dental professionals surveyed were also unsure if they were protected for virtual consultations.

The partnership will provide Dental Protection Xtra members with access to the Chairsyde platform at no additional charge, as part of their package. Dental Protection members who work at a Dental Protection Xtra practice are also eligible for a Chairsyde licence at no additional cost.

For more on how Chairsyde can support you and your practice visit https://chairsyde.com/dentalprotection.

\section{Rent an air compressor stress-free}

Why buy an air compressor when you can rent one, completely stress-free?

For a fixed rate starting from just $£ 14.95$ per week, Air Supply from DentalAir includes the installation of new equipment that delivers a medical standard sterile air supply and which is compliant to all standards and requirements.

Plus, you will benefit from all service costs included, 24-hour back-up support, a PSSR written scheme and air quality certification for CQC inspection purposes.

Designed by experts, fitted by perfectionists, serviced and supported by professionals - with Air Supply from DentalAir, you can ensure you have sterile air without the stress.

For more information, contact DentalAir at info@dentalair. com or call 08009757530 .

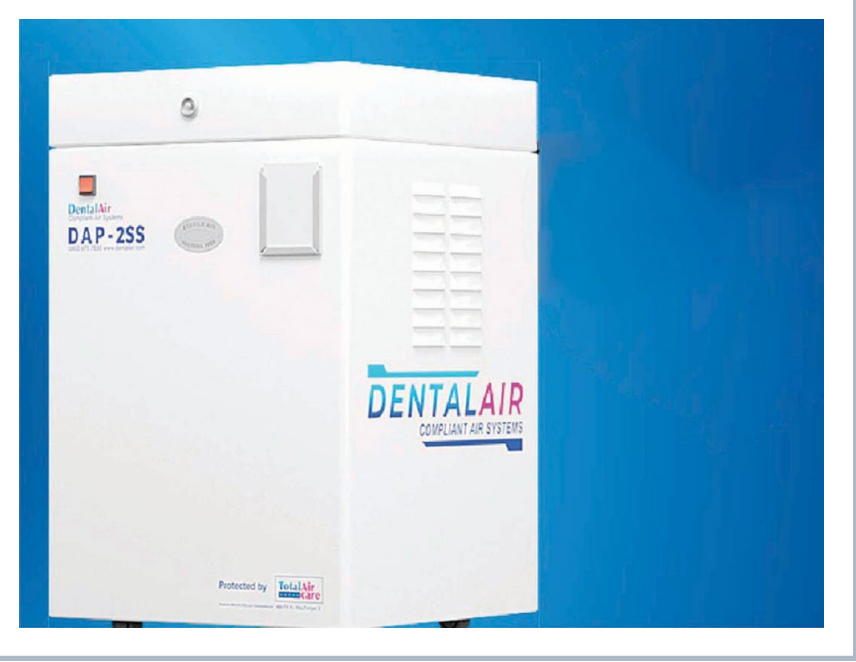

